\title{
Shallow Speleogenesis in a Coastal Carbonate Platform: Quintana Roo, Mexico
}
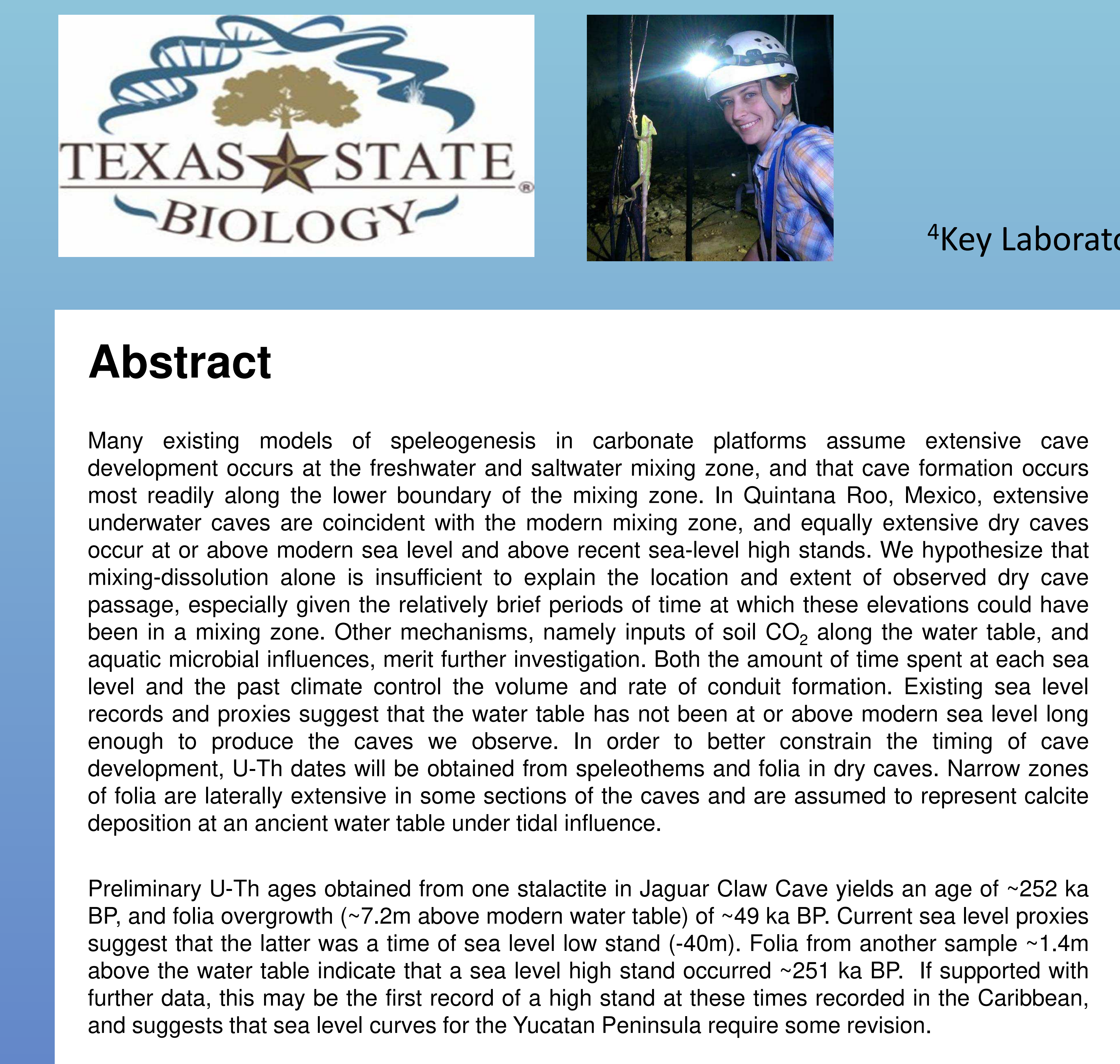

Site Location

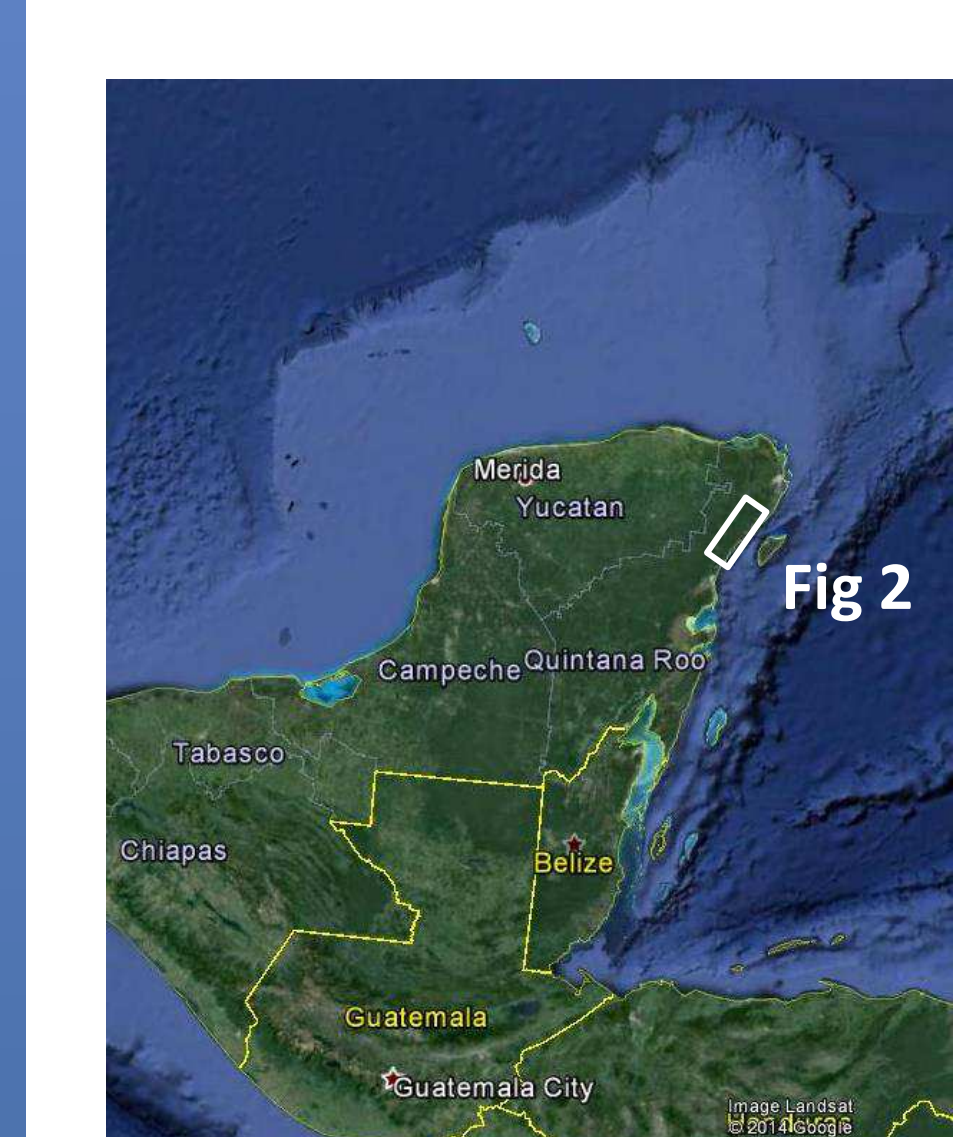

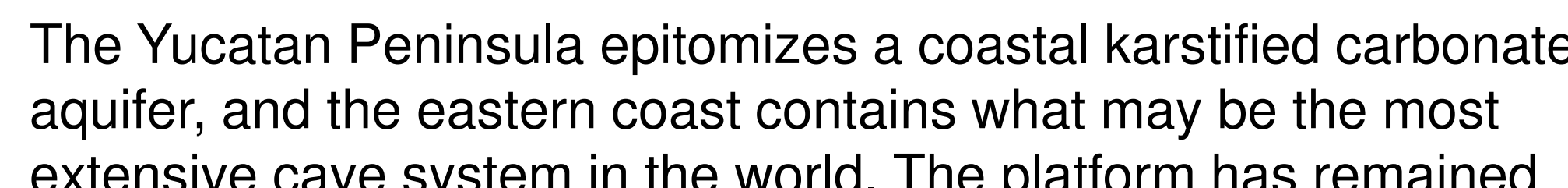

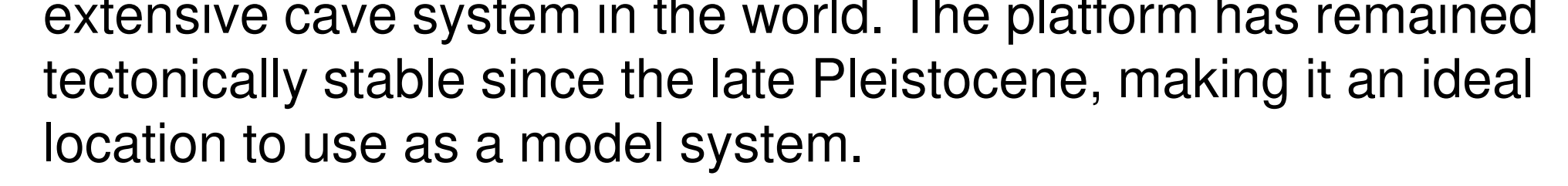

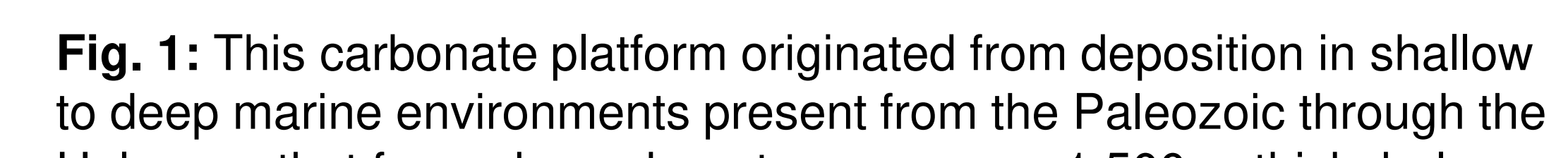

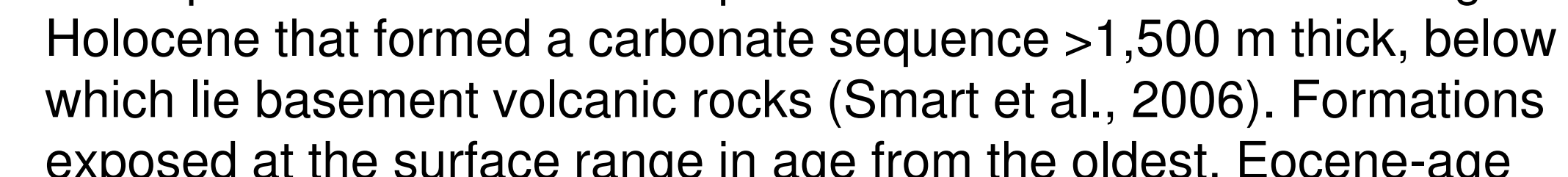

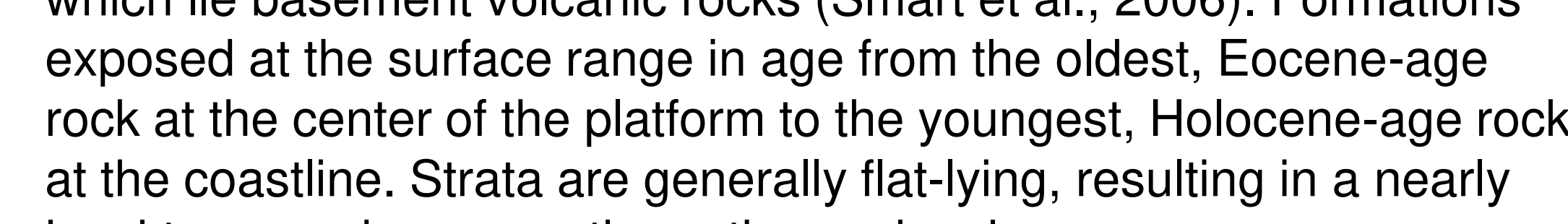

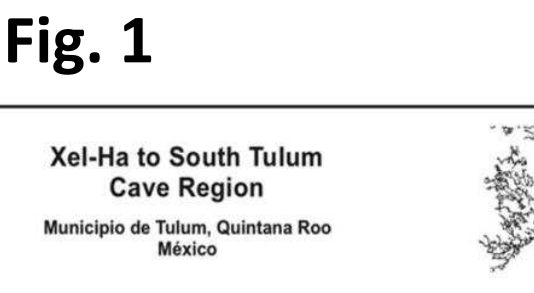

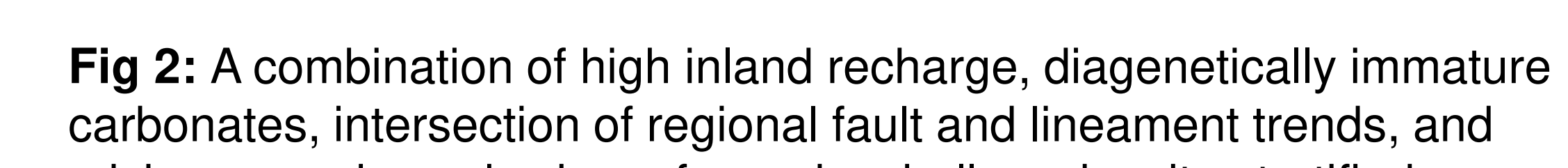

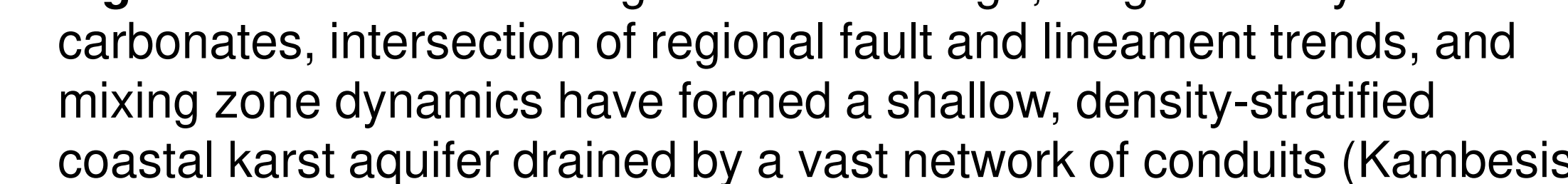

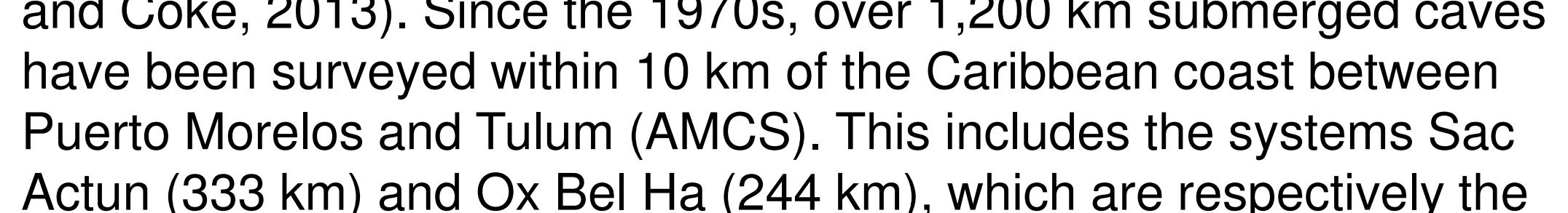

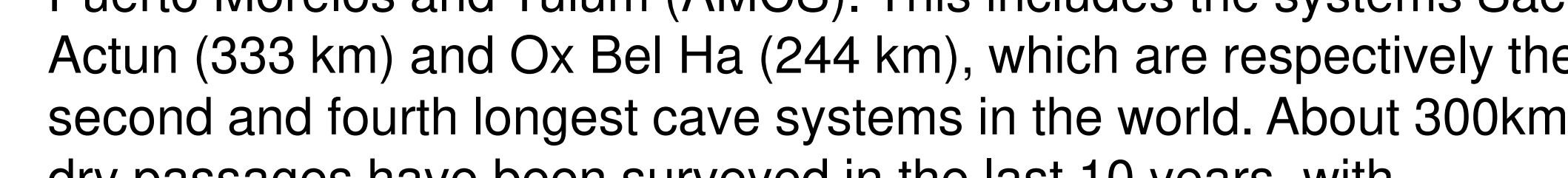

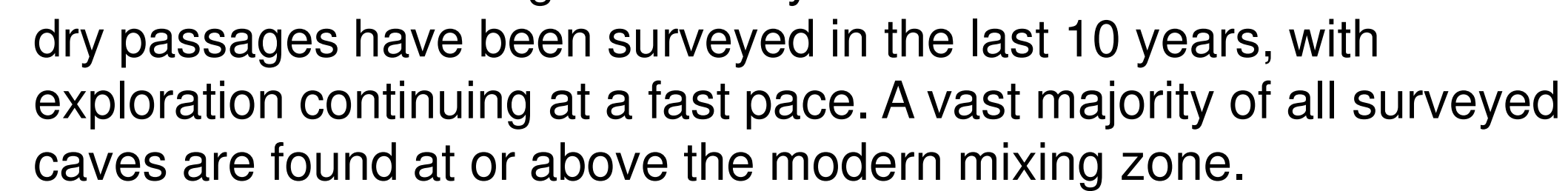

Aubri A. Jenson ${ }^{1}$, Benjamin F. Schwartz ${ }^{1,2}$, Yunxia Li3, ${ }^{3,4}$, Yongli Gao ${ }^{1}$ Dept. of Biology, Texas State University, San Marcos, TX
${ }^{2}$ Edwards Aquifer Research and Data Center, San Marcos, TX

${ }^{3}$ Center for Water Research, Department of Geological Sciences, University of Texas at San Antonio, San Antonio, TX

A Process Model of Coastal Speleogenesis
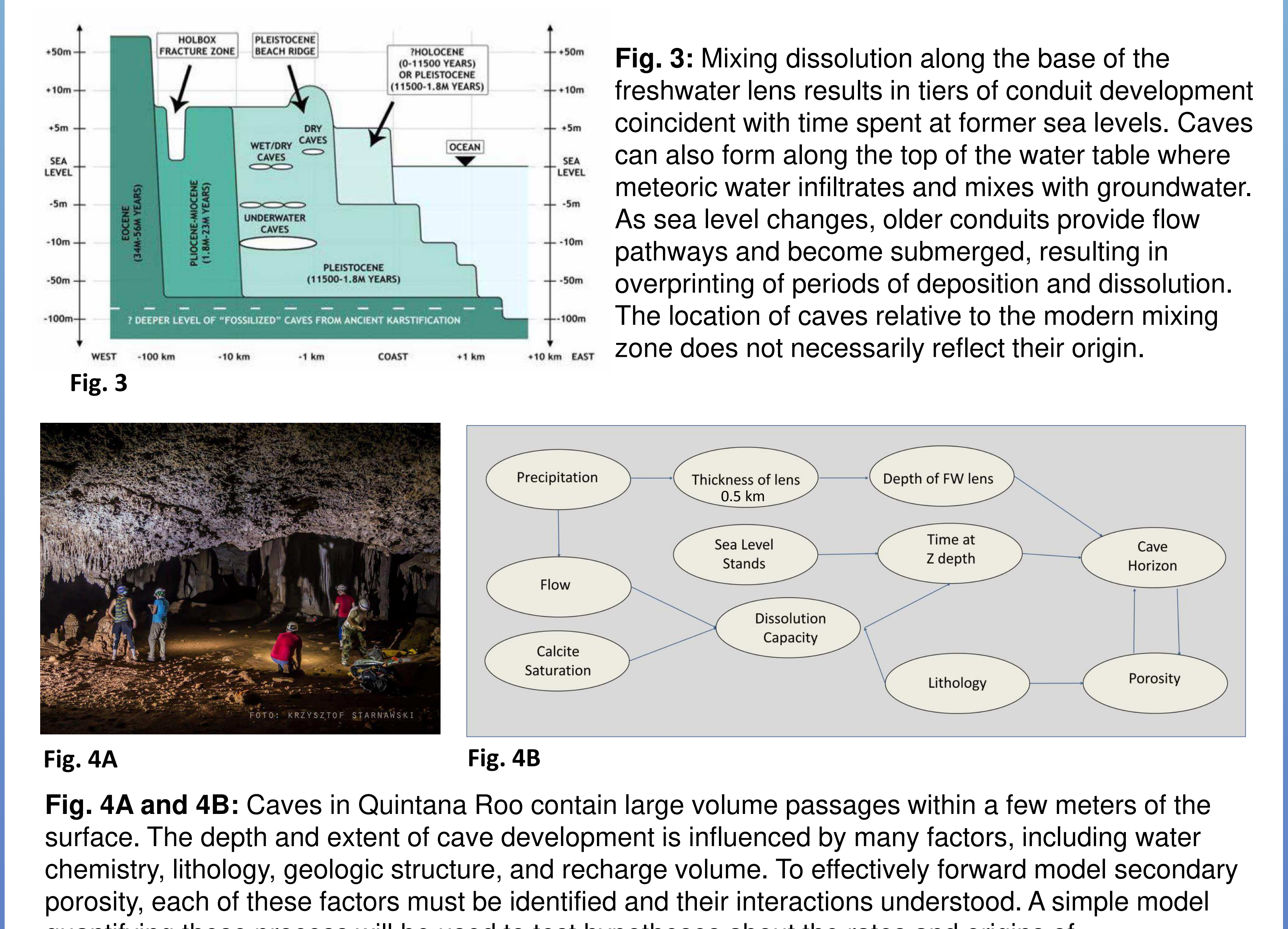

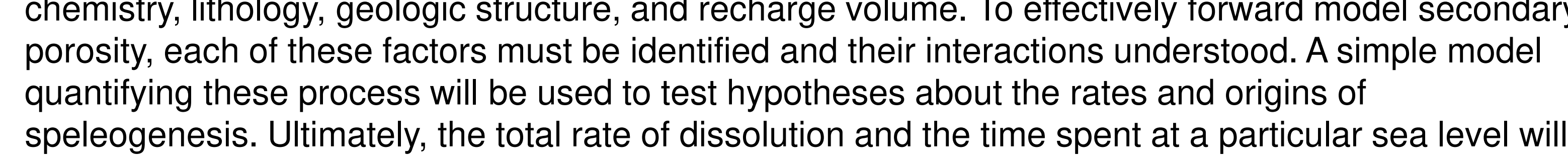

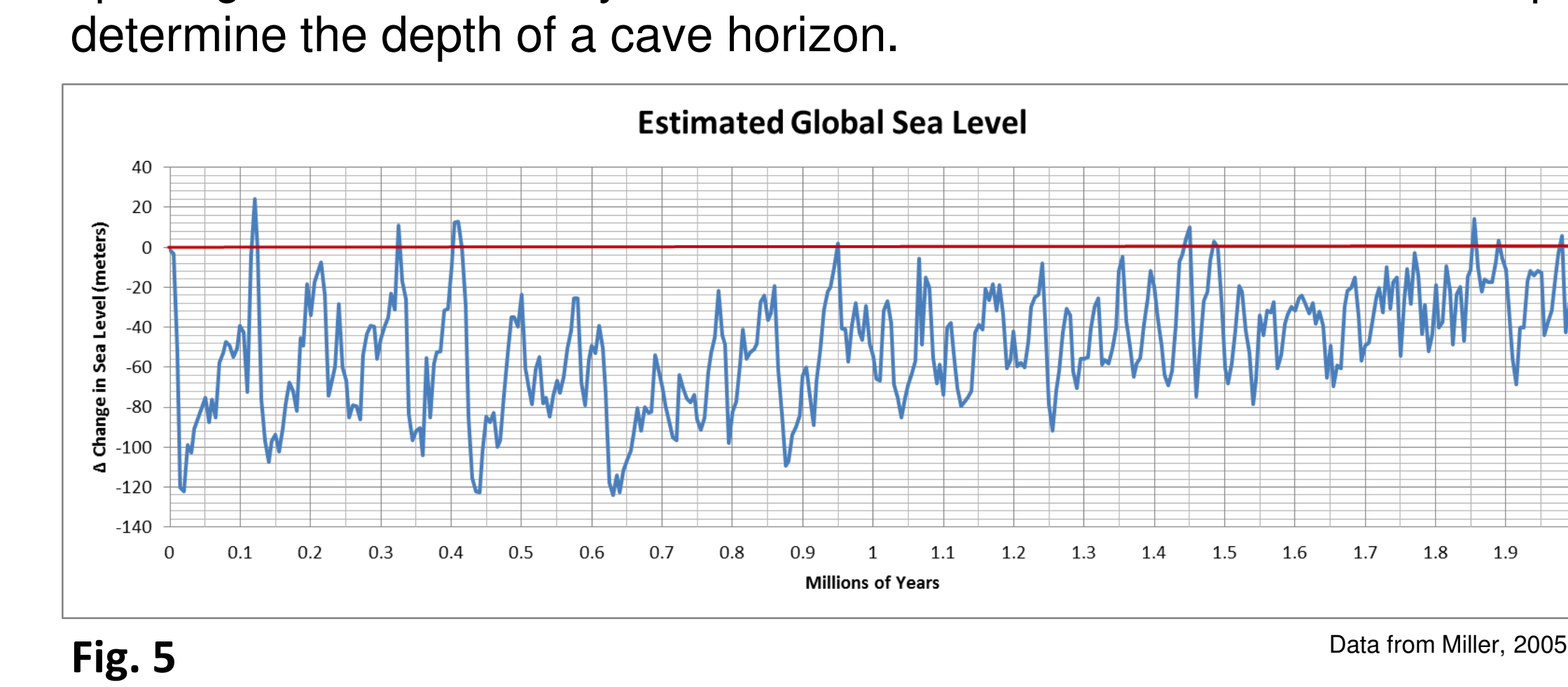
Fig 5: The Yucatan
Peninsula has been
subaerially exposed
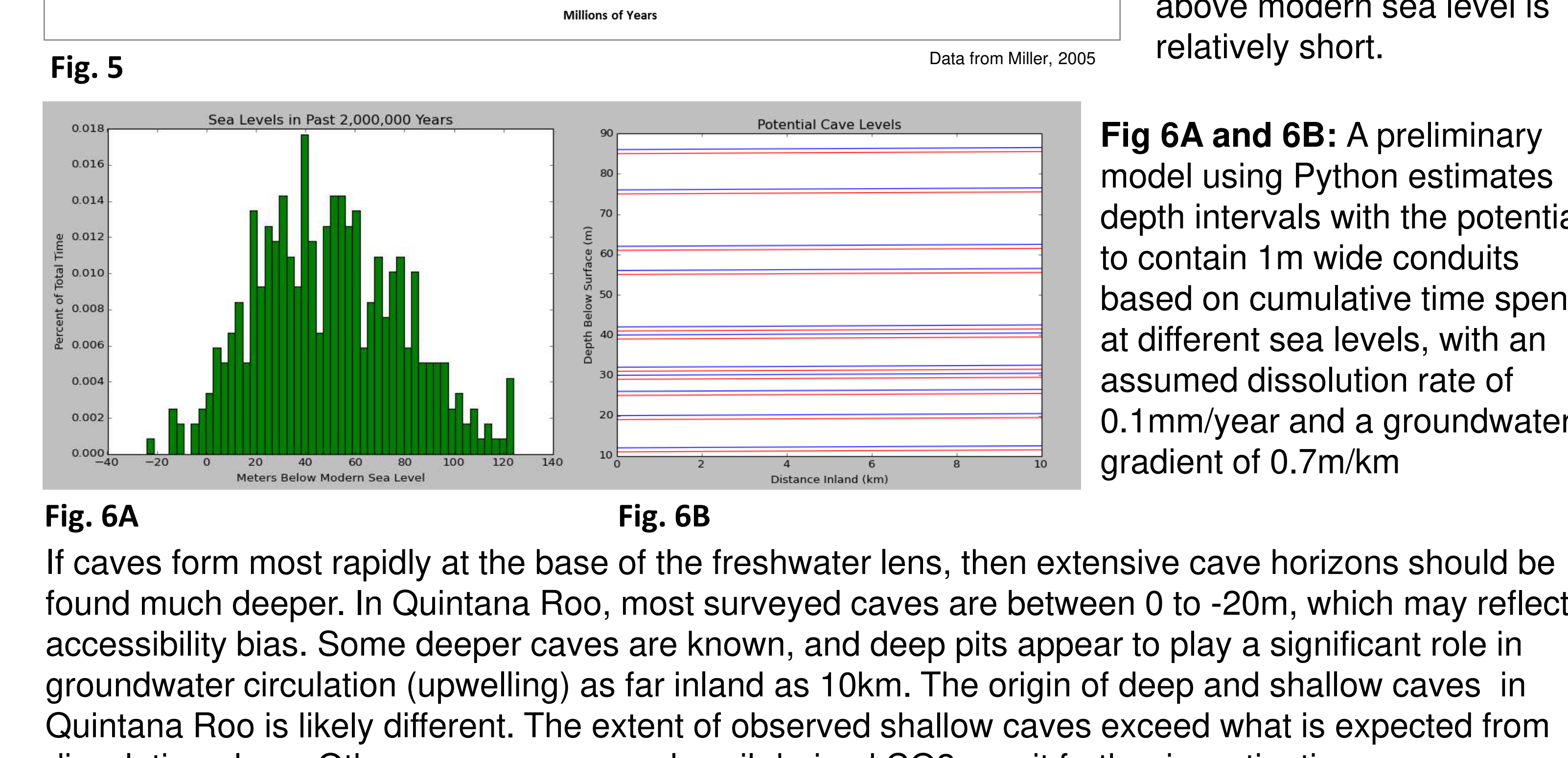

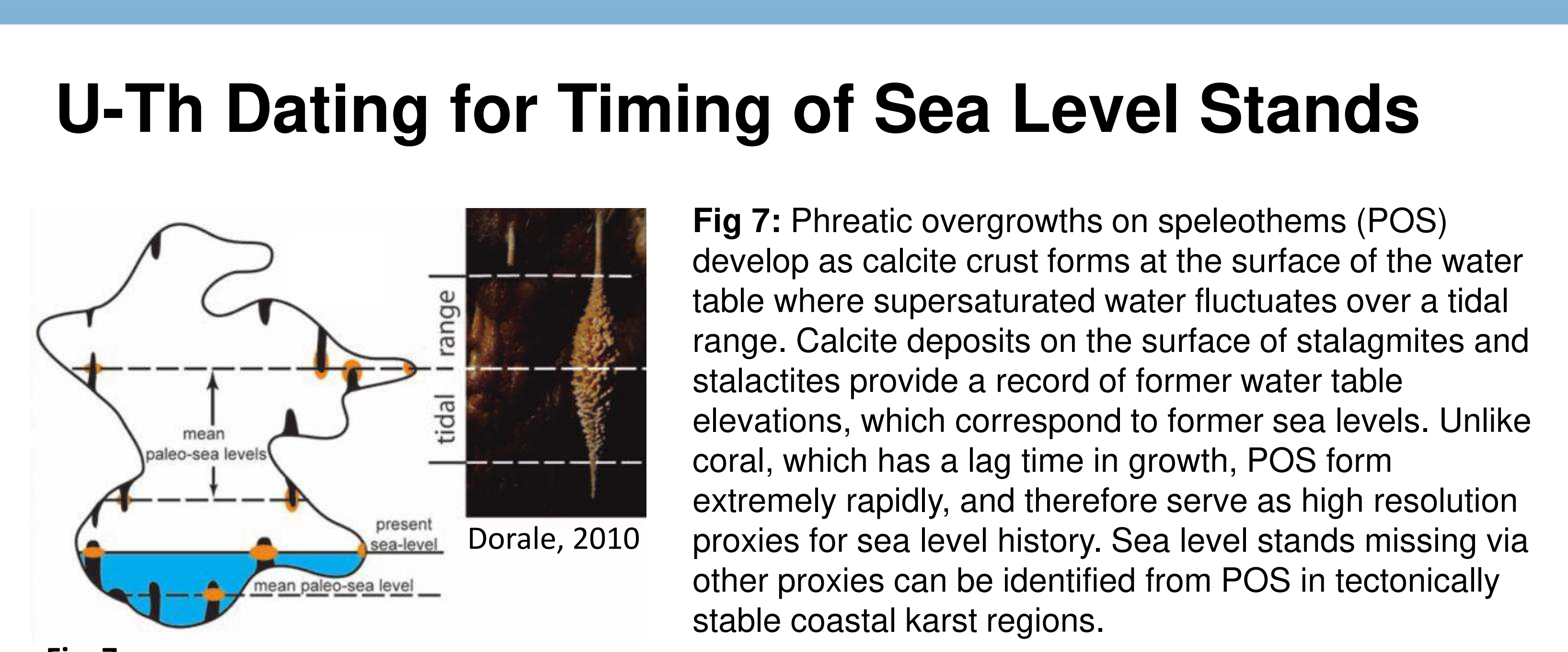

Fig. 7
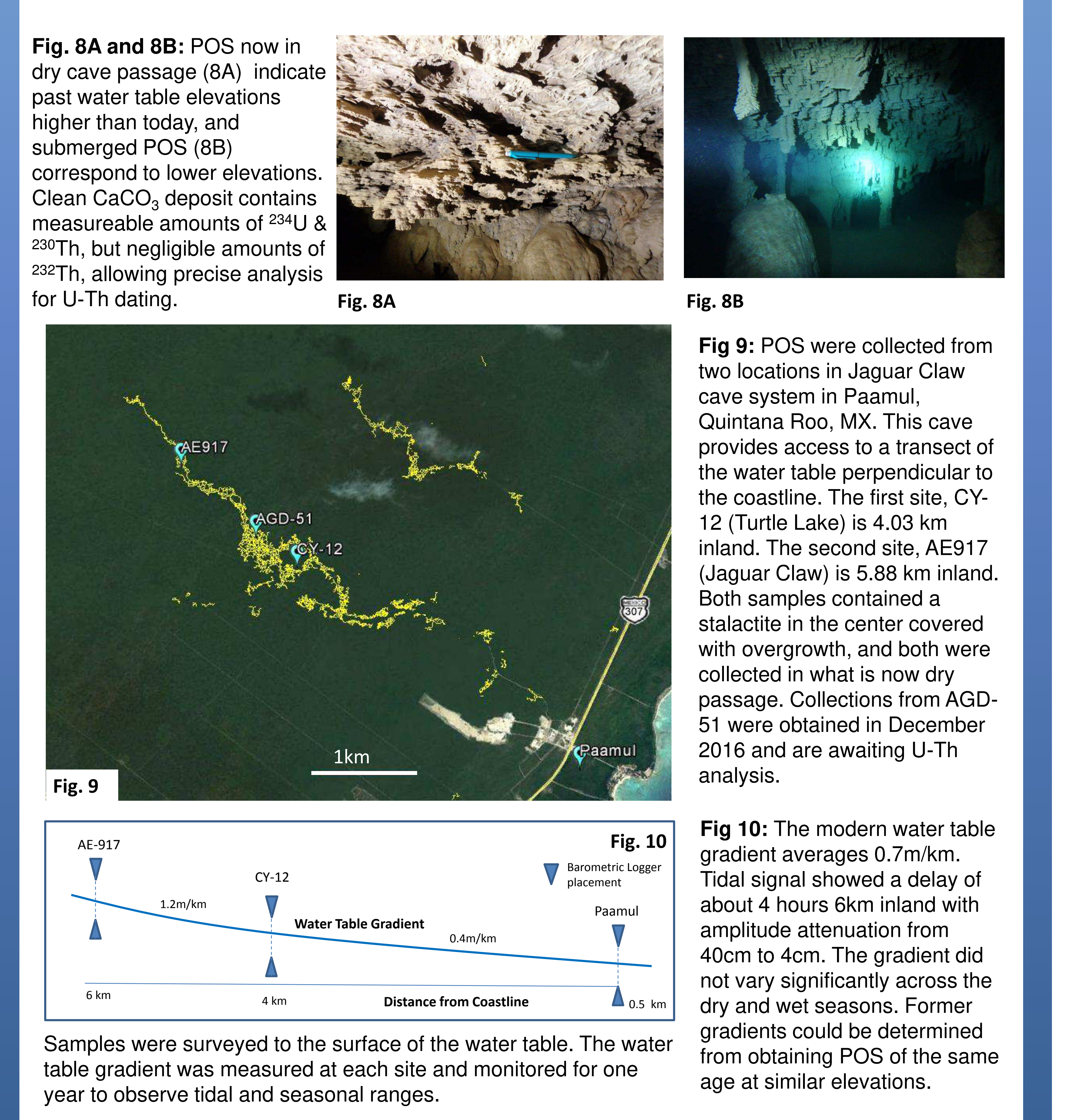

IUSA

Evidence of Rapid Sea level Change

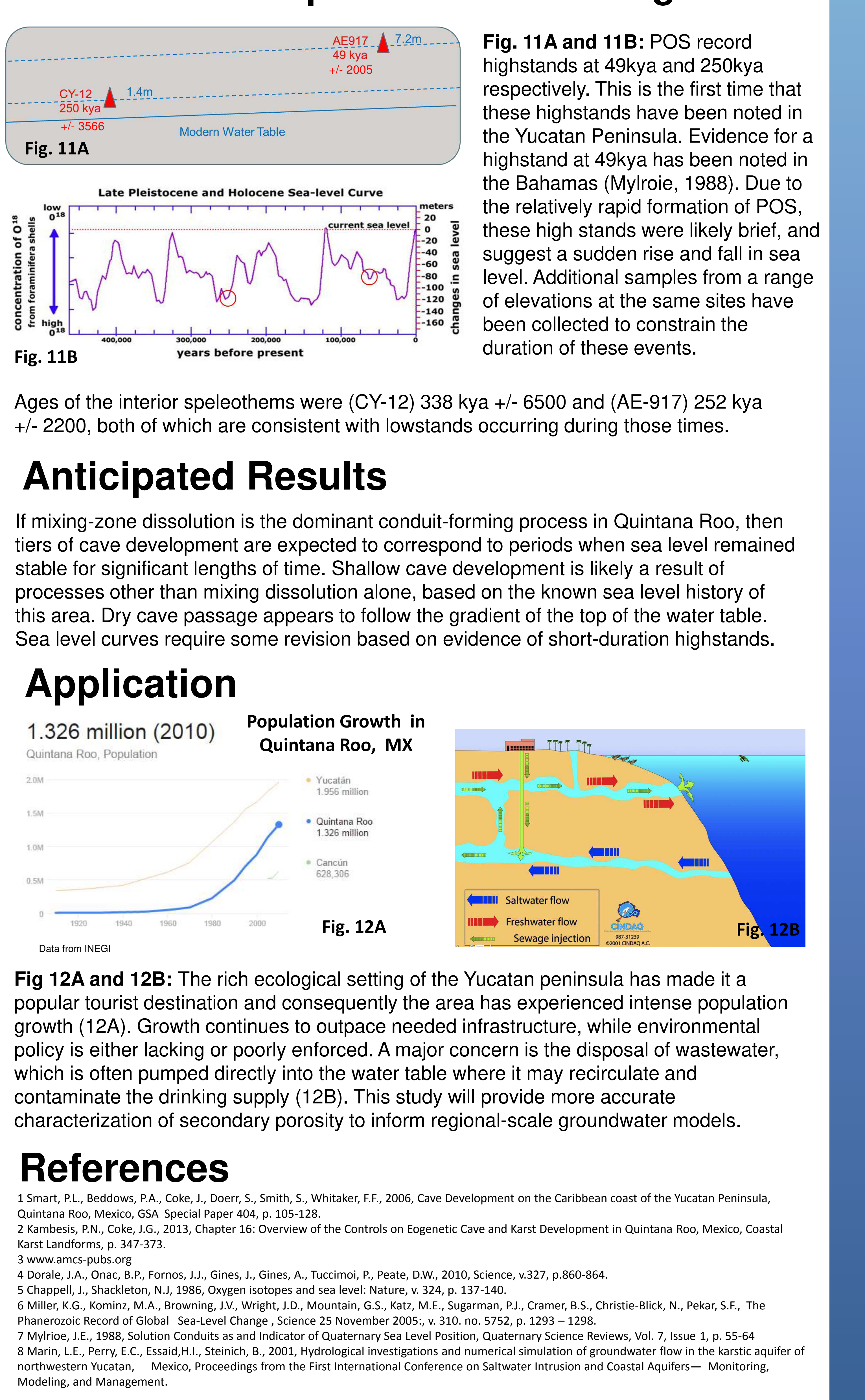

